\title{
Stability, Bistability, and Instability in Small Group Influence Patterns
}

\author{
Holly Arrow \\ University of Illinois at Urbana-Champaign
}

\begin{abstract}
Three models of change and continuity in group structure are tested using existing longitudinal data on 20 small groups. Groups met face to face or via a computer-mediated communication system for 13 weeks. Computer-mediated groups fit the robust equilibrium pattern best, with initial fluctuations in the influence hierarchy followed by a more stable structure that persisted despite changes in operating conditions. Face-to-face groups fit a bistable punctuated equilibrium pattem best, retaining their initial influence structure until an environmental cue triggered a shift. Contrary to the predictions of this model for radical change, adjustments were modest. Poor performance on tasks failed to trigger changes predicted by the adaptive response model, probably because outcomes were not very important to group members.
\end{abstract}

When a number of persons have come together to form a group, their behavior never holds to its first pattern. Homans, 1950, p. 109

Lasting patterns can appear as early as the first few seconds of a group's life. Gersick, 1988, p. 33

Traditional models of group development-the patterning of change and continuity in group structure and behavior over time-propose that groups follow a fixed sequence of stages (Bales, 1970; Bennis \& Shepard, 1956; Tuckman, 1965; Tuckman \& Jensen, 1977; see Mennecke, Hoffer, \& Wynne, 1992, for a review). These models typically presume a stable group composition and context and ignore external causes of change. Changes in group composition or other interventions are treated as externalities that disrupt the ideal path of development (Hill \& Gruner, 1973). Yet most naturally occurring groups with an extended history experience temporary or permanent changes of membership and cope (or fail to cope) with other changes

Holly Arrow, Department of Psychology, University of Illinois at Urbana-Champaign.

This article is based on my master's thesis, submitted to the University of Illinois, Urbana-Champaign, in 1994. I thank Joseph E. McGrath and Stanley Wasserman, who supervised the thesis. The research on which it is based was supported in part by National Science Foundation grants BNS 91-06501, IRI 91-07040, and SBR 93-10184 and by a National Science Foundation Graduate Research Fellowship.

I also thank Deborah H Gruenfeld, Andrea B. Hollingshead, Joseph E. McGrath, and Kathleen O'Connor, who planned and conducted the JEMCO Workshop study; Paul Franz, Kevin Gehrt, Martha Orland, Mike Samonds, Kristy Steimel, Brian Thomson, and others who assisted in the collection and processing of data; Joan Alster for statistical consulting; and Jennifer Berdahl for her advice.

A set of six papers analyzing different data from the same longitudinal study have been published as a special issue of Small Group Research (Vol. 24, August 1993). None of the analyses reported here have been previously published elsewhere.

Correspondence concerning this article should be addressed to Holly Arrow, who is now at Department of Psychology, 1227 University of Oregon, Eugene, Oregon 97403 . Electronic mail may be sent via the Internet to harrow@darkwing.uoregon.edu. in tasks, technology, and operating conditions over time. Proponents of nonsequential group development models emphasize the importance of contingencies in the environment that influence a group's developmental path (e.g., Gersick, 1991; McGrath, 1991; Poole \& Roth, 1989a, 1989b). According to these theorists, differences in group composition or task type should result in different patterns of change and continuity in group structure (patterns of interpersonal relations) and task behavior over time. Changes in these contingencies during the group's history should evoke responses by the group. To better understand the impact of both initial conditions and changes in conditions, they call for more research exploring the possibility of multiple developmental paths (Cissna, 1984; McCollom, 1995; McGrath \& O'Connor, 1996; Poole \& Roth, 1989b).

\section{The Dynamics of Group Structure: A Multiple-Path Approach}

This study takes up that challenge, using existing data from 20 groups of similar size and composition that met weekly for 13 weeks (see McGrath, 1993). Half the groups met face to face, and half used a computer conferencing system. Several of the groups had unplanned changes in group composition in the first few weeks, and with one exception, all had one or more absences. In addition, operating conditions were changed for all groups in two planned interventions. This article addresses three questions: (a) For task groups with a fixed duration operating in a changing environment, do patterns of change and continuity in group structure correspond to a particular model of group development? (b) Does communication medium affect which developmental pattern is followed? and (c) Does early disruption of group composition affect group development?

A better understanding of the contingencies underlying group development is important because different models identify different periods during which groups will be receptive to, resistant to, or disrupted by interventions. Supervisors who oversee and support work groups, for example, could benefit from knowing when groups need to be buffered from change and when they will welcome assistance in adapting to a changing environment. Imposed changes in group composition should have different 
effects on relational patterns and task performance depending on the timing of change (Arrow \& McGrath, 1995).

Established findings in social psychology, such as people's tendency to view in-group members as more heterogeneous than out-group members (Linville \& Jones, 1980), and people's tendency to cooperate with in-group members and compete with out-group members (Tajfel \& Turner, 1986), have been shown to depend on the stage of group development for the in-group in question (see Worchel, 1994, for a discussion of such group development effects).

Because the literature provides literally dozens of theories of group development (Hill \& Gruner, 1973, claim to have identified over 100), theory-driven investigation requires some initial consolidation. The next section extracts four basic models from the plethora of existing theories, and derives concrete, testable predictions for changes and continuity in group structure.

\section{Four Models of Change and Continuity in Group Structure}

The four models draw on typologies of both group development and organizational development (Allmendinger \& Hackman, in press; McCollom, 1995; Mennecke et al., 1992; Miller \& Friesen, 1980; Wanous, Reichers, \& Malik, 1984). They are also informed by complexity theory (Cowan, Pines, \& Meltzer, 1994) and dynamical systems theory, which identify basic patterns of change and evolution in both living and nonliving systems (Goemer, 1994).

The four models differ in their relative emphasis on internal and external causes of change. They also differ in whether and under what circumstances they predict abrupt change, gradual change, or relative stability in group structure. Sources and characteristics of change and continuity in the four models are summarized in Table 1. Although the empirical study that follows examines change and continuity in only one aspect of group structure - the patterning of interpersonal influence-the models presented here are intended to apply to group structure more generally. Broadly defined, group structure refers to the pattern of relations among group members (Levine \& Moreland, 1990). Theories of group development have addressed aspects such as leader-follower relations (e.g., Bion, 1961; Mann, Gibbard, \& Hartman, 1967); status and role systems (e.g., McGrath, 1991); distribution of influence and power (e.g., Poole \& Roth, 1989b; Worchel, 1994); cohesiveness (e.g., Poole \& Roth, 1989b; Tuckman, 1965); and conflict (e.g., Mann et al., 1967; Tuckman, $1965)$.

\section{Model 1: Robust Equilibrium}

The robust equilibrium model posits a brief period of fluctuation followed by a steady state. After an initial period of instability in relational structures, a stable influence hierarchy and role system will emerge and persist. Shocks that might disrupt the group's structure will be dampened by the group, hence variations will be small. Equilibrium is the normal state of the group; robust refers to the persistence of a stable structure despite changes in the environment.

The robust equilibrium model emphasizes internal causes of development in the initial period and structural stability and continuity thereafter. From a dynamical systems perspective, the group moves toward a single attractor (Abraham, Abraham, \& Shaw, 1990) and stays in the region of closely similar structures, with minor fluctuations. Equilibrium in this case is not rigidity but the stability achieved by an active, self-regulating system.

\section{Theoretical and Empirical Roots}

Equilibrium and homeostatic models have a long history in social and organizational psychology-from field theory (Lewin, 1951), to the equilibrium problem (Bales, 1953), to open systems theory (Katz \& Kahn, 1978), which draws in turn on general systems theory (Berrien, 1976; von Bertalanffy, 1968). More recent work extends this line of theorizing (e.g., Carley, 1991). Although equilibrium models acknowledge change (usually treated as gradual) as an aspect of group functioning, the emphasis is on achieving and actively maintaining a stable state. In organizational theory, institutional models (e.g., Zucker, 1977, 1987) stress the power of institutional processes to buffer established organizations against change and ensure continuity. Robust equilibrium also fits the population ecology approach to organizational change (Hannan \& Freeman, 1977, 1984), which proposes that stable systems are the most "fit." This theory proposes that changes in a population of organizations occur as new organizations are formed and unsuccessful ones (especially unstable ones) dissolve, and not through changes within established groups.

Some equilibrium models have been tested empirically. In a four-meeting study of five-person groups, Bales (1955) found that a simple, tentative group structure emerged (if at all) toward the end of the first meeting. This structure was challenged in the second meeting, resulting in either a confirmation of the first structure or an exchange of status positions between the top two or three members. Not all groups studied reached an equilibrium

Table 1

Characteristics of Change Among the Four Models of Group Development

\begin{tabular}{|c|c|c|c|}
\hline Model & Source of change & Nature of change & Source of continuity \\
\hline \multirow{4}{*}{$\begin{array}{l}\text { Robust } \\
\text { equilibrium } \\
\text { Life cycle } \\
\text { Punctuated } \\
\text { equilibrium } \\
\text { Adaptive } \\
\text { response }\end{array}$} & Internal forces & Initial fluctuations & Internal forces \\
\hline & Internal forces & Gradual, ongoing & External disruption \\
\hline & External cues & Radical, abrupt & Internal forces \\
\hline & External cues & Immediate or delayed response & External forces \\
\hline
\end{tabular}


state, but the presumption in this study was that all groups were striving to achieve "an equilibrated role structure"' (Bales, 1955 ). More recent theorizing on robust equilibrium in large groups (e.g., Carley, 1991) propose contingencies such as complexity and initial cultural homogeneity that determine the length of time before "perfect social stability" is reached.

\section{Psychological Processes Underlying the Model}

One explanation for the robust equilibrium pattern in initially unstructured groups can be found in the changing expectations of group members about one another (McGrath, Berdahl, \& Arrow, 1996). According to expectation states theory (Berger, Conner, \& Fisek, 1974) and social role theory (Eagly \& Karau, 1991), when strangers first come together in a group, members use easily observed status characteristics such as gender, race, or age as a basis for establishing the initial leadership and influence hierarchy. As members gain information on the actual abilities of one another through interaction, the structure may be adjusted to match the relevant skills of different members. In line with the robust equilibrium model, the outcome of this adjustment process would then be adopted as the normative structure for interpersonal relations in the group. Of course, when members' behavior is shaped by the expectations of others, this can reinforce preconceptions (Ridgeway, 1991). Adjustments based on imposed stereotypes may worsen the fit between relational patterns such as role and status systems and actual member skills and abilities.

A "constructural" explanation for robust equilibrium (Carley, 1991) proposes that stability emerges as members with initially distinct knowledge bases share information of all kinds with one another. Equilibrium in knowledge and behavior is established as shared knowledge overtakes unique information as a proportion of information contained in the group. This process presumes, of course, that membership remains quite stable.

\section{Predictions}

The robust equilibrium model defines equilibrium as a point of arrival that will be achieved within the first few meetings. According to this model, groups will show much stronger weekto-week continuity in structure once members have found their place in the status structure. Substantial changes in the environment may cause transient changes in the group structure, but the group will quickly revert to its normal pattern. Poor fit between an established structure and environmental demands will lead to failure, not adaptive change.

\section{Model 2: Life Cycle}

Life cycle models posit that groups pass through stages characterized by different structural patterns. In the first stage, an initial structure forms. In the second, this structure is contested and adjusted. In the third stage, the group settles on a normative structure. In the fourth stage, the group focuses on task performance, and over time, the structure becomes increasingly inflexible. Different groups may take more or less time to work through these stages. In the last stage, the structure changes again as the group dissolves the bonds that hold it together.

According to this model, change is the normal condition for groups, and this change follows an internal logic, with the resolution of each stage initiating the next. Life cycle changes do not rely on environmental cues, and the model emphasizes gradual as opposed to sudden or radical change. Environmental changes should have little effect on group development, although strong external shocks might retard progress.

\section{Theoretical and Empirical Roots}

The life cycle model is abstracted from group theories that fall into the categories of linear-progressive and life cycle models (Mennecke et al., 1992). Probably the best known is Tuckman's (1965) four-stage model, later expanded to five stages (Tuckman \& Jensen, 1977) : forming, storming, norming, performing, and adjourning. Other theories in this vein posit three stages (e.g., Hill \& Gruner, 1973), six stages (Bennis \& Shepard, 1956; Worchel, 1994), or four (e.g., LaCoursiere, 1980). Organizational life cycle literature ( see Whetten, 1987, for a review) also is unresolved on the number of stages. More broadly, the model is congruent with the idea of gradual, progressive change that pervades theories of child development, organizational theories of growth and decline, cumulative scientific development, and biological evolution (see Gersick, 1991, for a summary). Variants on the life cycle model include what Mennecke and colleagues (1992) term recurring cycle models. Some of these focus on the history of the group as a whole (e.g., Worchel, 1994 ); others focus on recurrent project cycles (e.g., Bales \& Strodtbeck, 1951; Bion, 1961; see McGrath \& O'Connor, 1996, for a review). For short-term groups with a single project, of course, the distinction is moot.

\section{Psychological Processes Underlying the Model}

The life cycle model presumes that different psychological problems or issues are prominent at different periods in the group's life (Bennis \& Shepard, 1956; Burnand, 1990) and that these issues have implications for the structure of interpersonal relations in a group, including influence patterns. Change is internally generated and follows a fixed developmental sequence. The emergence of structure in the first stage, for example, addresses members' discomfort in an ambiguous situation. Once uncertainty is reduced, a power struggle ensues to test the appropriateness of the initial structure (Stage 2). Once a stable structure is confirmed (Stage 3 ), performance becomes the main issue (Stage 4). In the final stage, attention shifts to the emotional issue of leave-taking, and the structure developed to facilitate performance dissolves.

\section{Predictions}

Groups that fit the life cycle model should undergo changes in structure, including fluctuation in influence patterns, in the first few meetings. After the conflict period is resolved, influence patterns should become increasingly stable until just before the group disbands. In the last few sessions, the group structure should dissolve. The emergence and transformation of group 
structure should be unrelated to changes in task, technology, or other operating conditions. A big change might temporarily interrupt group evolution, however, "freezing" existing patterns while group development is disrupted.

\section{Model 3: Punctuated Equilibrium}

In the punctuated equilibrium model, group structure is characterized by strong inertial forces that generate a stable equilibrium "punctuated" by periods of sudden, rapid change. According to this model, whatever structure emerges in a group's first interaction will persist whether or not it is optimal, or even satisfactory, for performance. Moderate changes in the environment will have no effect on group structure. However, when a shock to the system jolts the group out of its usual fixed pattern, an abrupt and radical restructuring will occur. The new structure that emerges will then persist unchanged until the next crisis. Alternately, a group may abruptly unravel and dissolve (extinction). This model combines continuity and abrupt change. Internal processes promote continuity, whereas external causes trigger change.

\section{Theoretical and Empirical Roots}

This model draws on punctuated equilibrium theories in biological evolution (Eldredge \& Gould, 1972; Gould, 1989) and group development (Gersick, 1988, 1989) that emphasize revolutionary rather than incremental change. Gersick found that both laboratory (1989) and naturally occurring (1988) project groups held to the pattern of interaction established in their first meeting until the project's temporal midpoint. In an extension of the theory, other triggers for change are proposed: a strong external intervention, a change in group composition, or any dramatically novel state of affairs (Gersick \& Hackman, 1990). A variation of this model proposes that serious disequilibrium can be generated either by external fluctuations or from internal events such as serious interpersonal conflicts among group members (Smith \& Gemmill, 1991).

Punctuated equilibrium models in organizational theory (Miller \& Friesen, 1980; Tushman \& Romanelli, 1985) specify gradual change during the equilibrium period that consolidates and exaggerates whatever tendencies (e.g., toward innovation or formalization ) are established at the outset. A small number of gestalts, which are coherent organizational patterns of interlocking environmental demands, group structure, and task strategy (Miller \& Friesen, 1980), are proposed to act as attractors that organizational forms converge toward over time. Groups in which members have unequal influence, for example, will become more unequal over time, whereas groups that tend initially toward subgroup cliques will become more divided over time. These organizational development models emphasize declining performance and threats to organizational survival as forces that rouse the organization to counteract inertial forces and adopt a different organizational design. Research in this tradition (e.g., Haveman, 1992) stresses the positive benefits of group or organizational restructuring in response to environmental changes.

\section{Psychological Processes Underlying the Model}

The rapid onset of a persistent equilibrium state is explained by the application of a schema or framework for behavior (Gersick, 1988) that is shared among members. This framework may include implicit agreements about what roles should be played and how role assignment should be decided. Instead of developing norms over several sessions, members simply enact a shared script or routine (Gersick \& Hackman, 1990) based on past experience. This script is then reinforced as part of the normative structure of the group (Bettenhausen \& Murnighan, 1985 ). Such shared frameworks or imported routines provide a prepackaged structure that enables the group to turn its attention immediately to task performance, rather than taking the time and energy to develop a customized structure tailored to the task, the environment, and the needs and abilities of individual members. Incremental changes during these periods are designed to increase the fit between structural variables, technology, control systems such as norms, and strategy (Tushman \& Romanelli, 1985).

The rapid change periods can be explained by a dual process model. Some strong cue triggers a switch from automatic processing to intentional processing (Bargh, 1994; Shiffrin \& Schneider, 1977), and group members abruptly notice problems in the fit between environmental demands and group functioning (including inappropriate structures) that have previously been ignored. This galvanizes members to make rapid and fundamental changes to improve the fit. The restructured group then resumes habitual task performance.

This analysis of underlying process also suggests a contingency that will determine whether or not a group follows the punctuated equilibrium pattern. When members lack an appropriate script or disagree on the basis for assigning members to positions, instant equilibrium is unlikely.

\section{Predictions}

Starting from the very first meeting, group structure should persist virtually unchanged from week to week, unless a marked change in the environment triggers a restructuring. After a brief unsettled transition, a new stable structure will emerge and persist. Groups will not return to their prior structure after the disruption. Hence patterns before and after a restructuring will show little similarity.

A strong external shock, a change in leadership (Miller \& Friesen, 1980), persistent poor performance (Tushman \& Romanelli, 1985), or a salient temporal milestone can trigger the instability and rapid change that allows a group to adjust its structure. For groups with a fixed life span and defined tasks, the midpoint can provide the trigger for restructuring (Gersick, 1988, 1989).

\section{Model 4: Adaptive Response}

The adaptive response model posits that groups actively create and adjust their structure in response to internal and external contingencies. According to this model, groups create or adopt structures to fit their task, their technology, and environmental demands. If operating conditions change, the group will adjust 
its structure in response. Whether the group exhibits structural stability, gradual change, or abrupt change depends on whether the demands of the environment remain stable, change slowly, or change abruptly.

If the task demands tight coordination among members, for example, groups will need a more formal, explicit communication and influence structure. Different decision rules, which imply different influence patterns, may be adopted for different types of decisions. Differential emphasis on task and social activity during periods of intense work or the socialization of new members may trigger members to take on different roles, which may change their relative influence in the group. Groups will also alter their structure in response to threat or failure.

The speed of adaptive response (immediate or delayed) will depend on how adept the group is at recognizing a change in circumstances and making needed adjustments. Detailed crisis contingency plans, for example, may be established. Gersick and Hackman (1990) proposed that groups that face frequent major changes may develop a meta-level habit that provides routines for switching to different frameworks. In organizations in which emergency situations are common, for example, specific routines may be developed and practiced. A hospital has one set of check-in procedures for the run-of-the-mill sick or injured, for example, and another for patients who arrive in critical condition. Military personnel have different norms for wartime versus peacetime operations.

\section{Theoretical and Empirical Roots}

The adaptive response model draws on the task performance school typified by Steiner (1972); sociotechnical theory (Trist \& Bamforth, 1951; see also Hulin \& Roznowski, 1985); the contingency theory of decision development (Poole \& Roth, $1989 \mathrm{~b}$ ) ; and organizational adaptation models (Lawrence \& Lorsch, 1967; Pfeffer \& Salancik, 1978).

Steiner (1972) noted that different task structures imply different weights for the contributions of different members; different influence structures should thus be optimal for different task types. In organizational settings, task and technology are closely intertwined: Technology shapes the tasks to be performed (Hulin \& Roznowski, 1985). However, the two can be varied independently in the laboratory. Kiesler and Sproull (1992) found that status differences were smaller in groups using computer-mediated communication (CMC) than in face-to-face (FTF) groups performing the same task (other studies, e.g., Berdahl \& Craig, 1996, have found opposite effects; see McGrath \& Hollingshead, 1994, for a review). Differences in structure based on communication technology would be expected on the basis of sociotechnical theory, which stresses the mutual adjustment and structuring of technical and social systems.

Contingency theory, which focuses on decision development, emphasizes that developmental paths are contingent and that groups actively seek to fit environmental demands (Poole \& Roth, 1989b). Hybrid models such as time, interaction, and performance (TIP) theory (McGrath, 1991) include both stages or phases (as in the life cycle model) and task and context contingencies for the appearance and ordering of stages. In dynamical-systems terms, the adaptive response model stresses the flexible switching of groups among a large array of possible structures (Kelso, 1995).

\section{Psychological Processes Underlying the Model}

Adaptive response can be explained using an informationprocessing perspective. Group members scan the environment for information relevant to task performance and group survival. Once the situation is defined as fitting a particular category, group members jointly enact an appropriate script. If the conditions persist unchanged, the group continues to reenact the script. If conditions change, group members will switch to a new script. Changes in structure will occur when different scripts specify different types of structure (e.g., concentration of power vs. equally weighted contributions).

\section{Predictions}

Because this model views environmental demands and operating conditions, not internal development, as primary, groups should change only in response to a perceived change in conditions or when performance is perceived to be poor. If operating conditions are stable and performance satisfactory, the group should not restructure.

\section{The JEMCO Workshop Study: 20 Groups Under Stable and Changing Conditions}

Existing data from an ongoing research program on time, task, and technology in work groups (McGrath, 1993) were used to test the robust equilibrium, punctuated equilibrium, and adaptive response models for 20 small groups that met for 13 consecutive weeks. (The life cycle model, unfortunately, could not be tested given the limitations of the data.) The groups were similar in size ( 3 or 4 persons) and composition (all but 1 included both sexes) and performed identical tasks in a fixed sequence. Given the experimentally imposed similarity in purpose, tasks, and meeting schedule among groups, adherence to a single developmental model seemed likely. Multiple developmental paths were also considered plausible, however, because of differences in communication technology, levels of membership change, and quality of task performance.

\section{Method}

\section{Procedure}

Participants were 81 students ( 37 men, 44 women) in an advanced course on the social psychology of organizations, who met weekly for 13 weeks in 3- or 4-person teams as the laboratory portion of the class. Members were assigned to teams on a quasi-random basis, given the constraints of student schedules. All groups except one included both sexes. The research component of the course was clearly described in the course catalog and on the first day of class.

The 13 weekly team meetings lasted $2 \mathrm{hr}$ each. Members were asked to consider themselves employees in the fictional "JEMCO" (J. E. McGrath Company) consulting organization, and each week their teams completed a consulting task for a fictional client. Task materials included a brief case description and detailed instructions about what type of solution or advice to generate. They were also told how the products would be scored. 
In Week 3, for example, group members read about a fictional company with a high incidence of alcohol abuse among employees. Groups were then asked to select among several policies designed to deal with the problem and to detail the reasons for their choices in a group rationale that explained why their choice would fit the company's criteria better than the alternatives. The rationale was scored for persuasiveness by multiple raters. In Week 10, groups were asked to apply the decision rules outlined in Vroom and Yetton's (1973) normative theory of leadership to four different scenarios and determine which management styles would be considered feasible. Choices were scored for consistency with the theory. (For detailed descriptions of the tasks for each week, see McGrath, 1993.)

After completing the group task each week, all members completed a standard questionnaire, which included questions about the relative infiuence of different members and the perceived quality of performance.

\section{Experimental Conditions and Manipulations}

Communications technology. The 13 weeks of the study included both planned manipulations in communications medium and in membership, and unplanned week-to-week changes such as absences. An overview is given in Table 2. Half of the groups were assigned to meet face to face in small rooms in which their interactions were videotaped; the other half communicated via a computer conferencing system that allowed each member to send messages to all other members. In Weeks 7 and 8, groups switched locations and used the other communication technology; in Week 9 they returned to their original setting and communication technology. This change in communication technology is relevant to those models that predict a change in group structure when there is a major change in operating conditions. Week 7 was also the temporal midpoint of the 13-week study.

Roles, status, and leadership. Groups were left to develop their own status systems and were not assigned specific roles, with one exception. In Weeks 8 and 9, groups performed role-playing negotiation tasks in which members were assigned to predetermined roles. One member had

Table 2

The JEMCO Workshop Study: Planned and Unplanned Changes and Manipulations

\begin{tabular}{|c|c|}
\hline Week & Manipulations and membership change \\
\hline 1 & Assignment to groups \\
\hline 2 & $\begin{array}{l}5 \text { groups get new members due to student drop/add; } 3 \\
\text { absences }\end{array}$ \\
\hline 3 & $\begin{array}{l}1 \text { group gets a new member due to drop/add; } 2 \text { groups } \\
\text { lose members }\end{array}$ \\
\hline 4 & 1 group loses a member; 1 absence \\
\hline 5 & 3 absences \\
\hline 6 & 6 absences (week before spring break); 1 drop \\
\hline 7 & Communication medium switched; 3 absences \\
\hline 8 & Role manipulation-week excluded from analyses \\
\hline 9 & $\begin{array}{l}\text { Role manipulation-week excluded from analyses; groups } \\
\text { return to regular medium }\end{array}$ \\
\hline 10 & 2 absences \\
\hline 11 & $\begin{array}{l}\text { Member switch--each group traded a regular member for } \\
\text { a temporary guest, round robin fashion; } 6 \text { absences }\end{array}$ \\
\hline 12 & Member switch continues; 5 absences \\
\hline 13 & $\begin{array}{l}\text { Members return to regular groups; } 2 \text { groups (besides the } \\
\text { chronic problem cases) fail to meet because of member } \\
\text { absences }\end{array}$ \\
\hline
\end{tabular}

Note. JEMCO $=$ J.E. McGrath Company (name of fictional consulting company). Two of the original 22 groups were excluded because of chronic attendance problems. final decision making power. In these weeks, relations between members were structured by the experimenters and did not reflect the naturally occurring structure of the group. Hence these weeks were excluded from the analyses.

Membership change and continuity. In Weeks 11 and 12 , one member from each group was switched to another group that was using the same communication technology as his or her regular group. Guest members returned to their usual groups in Week 13. In the first 2 weeks, 8 of the groups changed composition as students added or dropped the course or were absent for the second meeting. Over the 13 weeks, most of the groups had one or two absences. Two of the 22 groups in the original study had chronic attendance problems, with only 1 member showing up some weeks. These groups (1 FTF, 1 CMC) were excluded from analyses, leaving 10 groups for each communication condition.

\section{Measures}

Performance, perceived performance, and cohesiveness. Each of the weekly tasks called for a different group product. Because products were scored differently from week to week, all product scores were converted to $z$ scores. Each week, members rated the quality of task performance, their satisfaction with the group product, and their confidence in their group's performance on a 7-point scale. Internal consistency of this three-item scale of perceived performance quality was .95 (Cronbach's $\alpha$ for standardized variables).

Influence structure. Each week, each member ranked all group members, including self, from 1 (most influential) to $n$ (least infiuential) in group decision making. Judgments for each target member were averaged to yield a mean rank for each member, each week. Although not used in the analyses reported in this study, measurements of other aspects of structure were also available in the data set. The relative amount of influence for each member correlated positively with relative participation (.71), relative value of member contributions $(.78)$, and relative interpersonal popularity (.55). All correlations were significant at the $p$ $<.0001$ level. Thus influence structure can be considered a representative aspect of a cluster of attributes distinguishing relative member importance in the group.

Member judgments about one another's influence were arranged in a member-by-member matrix for each group. Intermember agreement about relative influence was calculated by comparing each pair of rows, summing the number of agreements, and dividing by the maximum agreements possible for a group of that size. This measure of interrater agreement yielded $52 \%$ agreement in judgments (exact matches in rankings of same target) for face-to-face groups and $47 \%$ agreement for computer-mediated groups. By chance, $17 \%$ agreement would be expected. Inspection of the matrices indicated that a common source of disagreement was members rating themselves as more influential than they were rated by others.

Continuity and change in influence structures. Kendall's Tau (Kendall, 1963) was used to measure similarity in the relative influence scores of members across weeks as indicated by their mean rank for each week. The coefficient is sensitive to inversions in order (Member A switches places with Member B as most influential) but indifferent to actual values (ranks, in this case). This is important because mean rank is sensitive to group size, which might change between weeks if a member was absent. For each group, the index was calculated for each pair of meetings that had at least two members in common. Values can range from -1 (complete inversion) to +1 (ordering preserved across weeks).

This measure ignores information on whether members changed their assessment of one another's relative influence from week to week, unless multiple members changed their judgments in the same direction. To capture this detailed information on the patterning of judgments by each member about each other member, an additional measure of change was 
calculated. Judgments were arranged in a sociomatrix with rows for judges and columns for targets of judgments. The quadratic assignment procedure (QAP) correlation (Hubert \& Schultz, 1976) was then used to calculate the similarity in sociomatrices between weeks. The algorithm available in UCINET IV (Borgatti, Everett, \& Freeman, 1992) computes Pearson correlation coefficients using corresponding cells of two sociomatrices. For each group, QAP correlations were calculated for each week-to-week comparison for which the sociomatrices had at least three cells in common. This measure also can take values from -1 to +1 .

To capture changes in both the overall influence hierarchy and in member-to-member judgments about relative influence, Kendall's Tau and QAP correlation scores (which correlated .66) were averaged to yield a "structural similarity" index of continuity in influence structures across weeks.

\section{Résults}

The analyses reported next examined whether the groups fit the patterns predicted by one or more of the models. Although multiple developmental paths were considered possible, all groups in the data set were of similar size and composition and performed identical tasks in the same order. Robust equilibrium, the midpoint version of punctuated equilibrium, and the performance contingency for adaptive response were tested. Because Weeks 8 and 9 had to be excluded from analyses, the data set was judged inadequate for a fair test of the life cycle model. Ambiguity about the timing of transitions between stages also made concrete predictions for the life cycle model impossible without a host of relatively arbitrary assumptions about where transitions should fall. Communication medium and early membership change were investigated as possible factors influencing the developmental patterns of the groups.

\section{Robust Equilibrium Supported for Computer-Mediated Groups}

For the robust equilibrium model, Week 1 structure was predicted to have low similarity to structure in Weeks 3 to 13. So scores on the structural similarity index should be low when comparing influence patterns in Week 1 with patterns for Weeks
3 to 13 . Structure during Weeks 3 to 13 was expected to be stable, so structural similarity scores were predicted to be high for all week-to-week comparisons among Weeks 3 to 13 . Week 2 was considered ambiguous, as the model does not specify how quickly equilibrium will be attained. The dependent variable for analyses was the mean similarity scores for week-to-week comparisons that were, according to the model, supposed to show either low or high continuity in influence patterns. The low and high categories were treated as two levels of a withingroups "model" factor. Communication medium (FTF or CMC) was included as a between-groups factor.

A 2 (communication medium) $\times 2$ (theoretically low or high structural similarity) analysis of variance indicated a Medium $\times$ Model interaction for structural similarity, $F(1,18)=7.55$, $p<.02$. Computer-mediated groups fit the predicted pattern, with structure in Weeks 3 to 13 showing substantially higher continuity than that between Week 1 and subsequent weeks. This pattern of initial fluctuation followed by relative stability fits the robust equilibrium model. In face-to-face groups, in contrast, structure in weeks 3 to 13 showed lower week-to-week continuity, violating the predicted pattern. Table 3 shows the means and standard deviations.

\section{Feeble Support for Punctuated Equilibrium With a Midpoint Transition}

The "midpoint transition" version of the punctuated equilibrium model was tested following the same procedure, but with different week-to-week comparisons coded as low or high. Structure in Weeks 1-6 (before the transition) and in Weeks 7-13 (after the transition) was expected to show high interweek similarity. Comparisons of structure in weeks before and after the midpoint, however, were expected to show relatively low structural similarity.

Results indicated a main effect across groups for model factor (low or high) for the punctuated equilibrium model, $F(1,18)=$ $4.65, p<.05$. There was no significant effect for communication medium, although effect size for the model was somewhat larger

Table 3

Similarity in Influence Structure for Week-by-Week Comparisons That the Models Predicted Would Show High or Low Continuity

\begin{tabular}{|c|c|c|c|c|}
\hline \multirow[b]{2}{*}{ Model } & \multicolumn{2}{|c|}{$\begin{array}{c}\text { Face-to-face } \\
(n=10)\end{array}$} & \multicolumn{2}{|c|}{$\begin{array}{l}\text { Computer- } \\
\text { mediated } \\
(n=10)\end{array}$} \\
\hline & $M$ & $S D$ & $M$ & $S D$ \\
\hline \multicolumn{5}{|l|}{ Robust equilibrium } \\
\hline Week 1 compared with Weeks 3-13 (low) & .23 & .20 & .09 & .31 \\
\hline Weeks $3-13$ compared (high) & .17 & .20 & .28 & .22 \\
\hline \multicolumn{5}{|l|}{ Punctuated equilibrium } \\
\hline Weeks $1-6$ compared with Weeks $7-13$ (low) & .14 & .22 & .20 & .28 \\
\hline Weeks $1-6$ compared; 7-13 compared (high) & .25 & .18 & .26 & .21 \\
\hline
\end{tabular}

Note. Structural similarity scores could take values ranging from -1 to +1 . Maximum values were restricted by low interrater reliability (.52 face-to-face, .47 computer-mediated communication) in member judgments about relative influence. When high scores are substantially higher than low scores, the patterns of change and continuity in influence scores fit the predictions of the model. 
for the face-to-face groups than for the computer-mediated groups (see Table 3 for means). Although the midpoint appears to have inspired some adjustments to structure beyond the normal week-to-week variability, the groups do not show a marked midpoint transition. Readers should keep in mind that the midpoint corresponded to the imposed change in communication media. Thus the results also indicate that the manipulation of communication technology had relatively mild effects on the stability of influence structures.

\section{Adaptive Response to Poor Performance Not Supported}

Unlike the robust and punctuated equilibrium models, which allow relatively straightforward predictions, change and continuity for the adaptive response model depend on task, technology, and environmental contingencies and on group perceptions. Unacceptably poor performance is one spur to adaptive change. However, performance deficits per se do not necessarily drive change; perceived deficits do. If groups responded to good performance by sticking with their current structure and strategy, and responded to poor performance with adjustments in structure, we would expect perceived performance at Time $t$ to be positively correlated with structural stability at Time $t+1$.

To test this possibility, correlation coefficients were calculated between perceived performance in Weeks 1 through 5 with structural stability (compared with the prior week) in Weeks 2 through 6 , respectively (later weeks were excluded because technology and membership manipulations confused the picture). Two of the five correlations were positive, three were negative, and none were significant. Increasing the lag to 2 weeks, four correlations were calculated, between perceived performance in Weeks 1 to 4 and structural stability for Weeks 3 through 6 , respectively. All four correlations were positive, but not significantly so at the .05 level adjusted for multiple comparisons. Relations between structural stability and cumulative perceived performance (calculated by averaging judgments in all prior weeks) also failed to show significant effects, although all correlations were positive. Failure to adjust based on perceived performance problems turned out to be wise: Standardized prod- uct scores and perceived quality of performance were negatively correlated $(-.33, p>.1, n=20)$ for Weeks 1 through 6 .

\section{Early Member Change as a Contingency Affecting Development}

To investigate the possible impact of early stability or instability in membership on the subsequent development of groups, the analyses for robust equilibrium and punctuated equilibrium were rerun with member stability as an additional factor. The general linear model procedure in SAS (SAS Institute, 1989) was used to accommodate the unequal cell sizes. Results indicate a Model $\times$ Medium $\times$ Member Stability interaction for structural stability, $F(1,16)=9.45, p<.01$. Early member change had no effect on the teridency of groups to adhere to punctuated equilibrium predictions, but it did affect the tendency of computer-mediated groups to follow robust equilibrium patterns. The seven CMC groups with consistent member composition fit the model well; the three CMC groups with early membership change did not fit model predictions (see Table 4). Mean continuity for the latter were high because of a single high-continuity group.

\section{Discussion}

The questions that motivated the study of the 20 task groups were (a) Do patterns of change and continuity in group structure correspond to a particular model of group development? (b) Does communication medium affect which developmental pattern is followed? and (c) Does early disruption of group composition affect group development? The data set used allowed a test of the robust equilibrium model, the midpoint version of the punctuated equilibrium model, and the poor performance contingency for the adaptive response model. A limitation of the study is its focus on changes in a single aspect of structure-influence patterns. However, high correlations between influence, participation, value of member contributions, and popularity indicate that other aspects of structure were closely related to influence patterns.

Table 4

Similarity in Influence Structure for Week-to-Week Comparisons Specified by the Robust Equilibrium Model, for Computer-Mediated Groups With and Without Early Membership Change

\begin{tabular}{lccccc}
\hline & \multicolumn{3}{c}{ Computer-mediated groups $(n=10)$} \\
\cline { 2 - 6 } & \multicolumn{2}{c}{$\begin{array}{c}\text { Early member } \\
\text { change } \\
(n=3)\end{array}$} & & & $\begin{array}{c}\text { Early member } \\
\text { stability } \\
(n=7)\end{array}$ \\
\cline { 2 - 6 } \multicolumn{1}{c}{ Robust equilibrium } & $M$ & $S D$ & & $M$ & $S D$ \\
\hline Week 1 with Weeks 3-13 (low) & .44 & .33 & -.06 & .12 \\
Weeks 3-13 (high) & .37 & .34 & .25 & .17 \\
\hline
\end{tabular}

Note. Structural similarity scores could take values ranging from -1 to +1 . Maximum values were restricted by low interrater reliability ( .52 face-to-face, .47 computer-mediated communication) in member judgments about relative influence. When high scores are substantially higher than low scores, the patterns of change and continuity in influence scores fit the predictions of the robust equilibrium model. 
Groups overall showed a slight change in the stability of influence patterns corresponding to the punctuated equilibrium model, with a somewhat larger change for FTF groups: The magnitude of change, however, hardly qualifies as a "restructuring." Communication medium did matter: Changes in influence patterns in CMC groups fit the robust equilibrium model quite well, but only if early membership composition was consistent.

The groups examined in this study were small, fixed-term teams whose members met once a week over the course of a semester. Unlike the single-project groups studied by Gersick $(1988,1989)$, these groups showed only slight evidence of a punctuated equilibrium midpoint pattern. Interpretation of the apparent tendency to adjust group structure is also muddied by the correspondence of the midpoint with an outside intervention that changed the groups' communication technology. Thus we don't know whether the groups were showing a modest adaptive response to a change in technology or a feeble response to a temporal cue. The groups also differed from those studied by Gersick in another way. Instead of working on a single large project, they received a new task each week that had to be completed by the end of the meeting. Thus they did not need to rely on temporal cues to pace themselves over the course of a semester.

One explanation for the computer-mediated groups' adherence to the robust equilibrium pattern, showing early instability in influence structure instead of "instant" equilibrium, is that members had no consensus script for how to run a task group communicating on computers. Lacking the rich interpersonal cues of the face-to-face medium, they may have found it more difficult to evaluate contributions from different members in making decisions, as diffuse status cues such as race, gender, and physical attractiveness were either unavailable or much weaker. Upper level students assigned to face-to-face groups, however, were likely to have past experience working in similar classroom project groups and thus could adopt an acceptable structure quickly. Faced with the switch to computer mediation in Week 7 , however, they may have found that their established influence patterns did not work as well. A separate study of these groups (O'Connor, Gruenfeld, \& McGrath, 1993) found that conflict increased when groups were switched to an unfamiliar medium, supporting this interpretation.

Groups did not adjust their influence structure in response to perceived performance problems. Performance on the tasks had no impact on students' course grades, however, so the incentive to make corrective changes was weak. The range of possible contingencies affecting influence structures is much broader than performance. Indeed, one of the assumptions underlying the adaptive response model-that groups adapt their structure to fit the demands of task, technology, and other environmental features - was supported by the different paths taken by groups using different communication media.

This study articulated four general models of group development, specified predictions for versions of three of the models, and compared the fit of observed structural change patterns with the predicted patterns. The life cycle model could not be tested adequately with this data.

Longitudinal studies can help researchers to better understand the multiple paths that groups take in elaborating and transforming the pattern of interpersonal relations. Many more com- parisons across multiple groups studied over time will be necessary to identify which features of groups and their environments predispose them toward one pattern or another. Variables not addressed in the current study, for example, include the purpose for which the groups were formed and the relative importance of the members, the technology, and the group tasks in shaping group structure (see Arrow \& McGrath, 1995, for a typology of groups based on these distinctions).

All studies of group development over time, whether they focus on many groups or few, stable or rapidly changing conditions, could benefit from deriving concrete, testable predictions from a few core models and testing those predictions systematically. More attention to the underlying processes purported to drive change and maintain continuity may yield a better basis for theorizing about the types of conditions that predispose groups to follow one model or another.

It is, of course, expensive in time and resources to gather longitudinal data on multiple groups under controlled conditions. However, as the JEMCO Workshop paradigm illustrates (McGrath, 1993), it is possible to accomplish this within a classroom context. Content coding of published case studies supplemented by retrospective questionnaires (an approach followed by Miller \& Friesen, 1980) and archival analysis supplemented by sample surveys and interviews (Allmendinger \& Hackman, in press) are some promising multimethod strategies for studying naturally occurring groups and sorting out the contingencies determining different basic patterns of development. More traditional experimental approaches using groups that meet for only a brief period have also succeeded in demonstrating group development effects (Worchel, 1994). The generality of group development patterns for groups of markedly different duration remains, however, an open question, one amenable to empirical research.

\section{References}

Abraham, F. D., Abraham, R. H., \& Shaw, C. S. (1990). A visual introduction to dynamical systems theory for psychology. Santa Cruz, CA: Aerial Press.

Allmendinger, J., \& Hackman, J. R. (in press). Organizations in changing environments: The case of East German symphony orchestras. Administrative Science Quarterly.

Arrow, H., \& McGrath, J. E. (1995). Membership dynamics in groups at work: A theoretical framework. In B. M. Staw \& L. L. Cummings (Eds.), Research in Organizational Behavior, 17, 373-411. Greenwich, CT: JAI Press.

Bales, R. F. (1953). The equilibrium problem in small groups. In T. Parsons, R. F. Bales, \& E. A. Shils (Eds.), Working papers in the theory of action (pp. 111-161). Glencoe, IL: Free Press.

Bales, R. F. (1955). Adaptive and integrative changes as sources of strain in social systems. In A. P. Hare, E. F. Borgatta, \& R. F. Bales (Eds.), Small groups: Studies in social interaction (pp. 127-131). New York: Knopf.

Bales, R. F. (1970). Personality and interpersonal behavior. New York: Holt, Rinehart \& Winston.

Bales, R. F., \& Strodtbeck, F. L. ( 1951). Phases in group problem solving. Journal of Abnormal and Social Psychology, 46, 485-495.

Bargh, J. A. (1994). The four horsemen of automaticity: Awareness, intention, efficiency and control in social cognition. In R. S. Wyer, Jr., \& T. K. Srull (Eds.), Handbook of social cognition (2nd ed.; Vol. 1, pp. 1-40). Hillsdale, NJ: Erlbaum. 
Bennis, W. G., \& Shepard, H. A. (1956). A theory of group development. Human Relations, 9, 415-437.

Berdahl, J. L., \& Craig, K. M. (1996). Equality of participation and influence in groups: The effects of communication medium and sex composition. Computer Supported Cooperative Work (CSCW), 4, 179-202.

Berger, J., Conner, T., \& Fisek, M. H. (Eds.). (1974). Expectations states theory: A theoretical research program. Cambridge, MA: Winthrop.

Berrien, F. K. (1976). A general systems approach to organizations. In M. D. Dunnette (Ed.), Handbook of industrial and organizational psychology (pp. 41-62). Chicago: Rand McNally College Publishing.

Bettenhausen, K. L., \& Murnighan, J. K. (1985). The emergence of norms in competitive decision-making groups. Administrative Science Quarterly, 30, 350-372.

Bion, W. R. (1961), Experiences in groups and other papers. New York: Basic Books.

Borgatti, S. B., Everett, M. G., \& Freeman, L. C. (1992). UCINET IV Version 1.0. Columbia, SC: Analytic Technologies.

Burnand, G. (1990). Group development phases as working through six fundamental human problems. Small Group Research, 21, 255-273.

Carley, K. (1991). A theory of group stability. American Sociological Review, 56, 331-354.

Cissna, K. N. (1984). Phases in group development: The negative evidence. Small Group Behavior, 15, 3-32.

Cowan, G. A., Pines, D., \& Meltzer, D. (Eds.). (1994). Complexity: Metaphors, models, and reality. Santa Fe Institute Studies in the Sciences of Complexity, Proceedings Volume 19. Reading, MA: AddisonWesley.

Eagly, A. H., \& Karau, S. J. (1991). Gender and the emergence of leaders: A meta-analysis. Journal of Personality and Social Psychology, $60,685-710$.

Eldredge, N., \& Gould, S. J. (1972). Punctuated equilibria: An alternative to phyletic gradualism. In T. J. M. Schopf (Ed.), Models in paleobiology (pp. 82-115). San Francisco: Freeman, Cooper, \& Co.

Gersick, C. J. G. (1988). Time and transition in work teams: Toward a new model of group development. Academy of Management Journal, $31,9-41$.

Gersick, C. J. G. ( 1989). Marking time: Predictable transitions in task groups. Academy of Management Journal, 32, 274-309.

Gersick, C. J. G. (1991). Revolutionary change theories: A multilevel exploration of the punctuated equilibrium paradigm. Academy of Management Review, 16, 10-36.

Gersick, C. J. G., \& Hackman, J. R. (1990). Habitual routines in taskperforming groups. Organizational Behavior and Human Decision Processes, 47, 65-97.

Goemer, S. (1994). Chaos and the evolving ecological universe. Langhorne, PA: Gordon \& Breach.

Gould, S. J. (1989). Punctuated equilibrium in fact and theory. Journal of Social Biological Structure, 12,117-136.

Hannan, M. T., \& Freeman, J. (1977). The population ecology of organizations. American Journal of Sociology, 82, 929-964.

Hannan, M. T., \& Freeman, J. ( 1984). Structural inertia and organizational change. American Sociological Review; 49, 149-164.

Haveman, H. A. (1992). Between a rock and a hard place: Organizational change and performance under conditions of fundamental environmental transformation. Administrative Science Quarterly, 37, 4875.

Hill, W. F., \& Gruner, L. (1973). A study of development in open and closed groups. Small Group Behavior, 4, 355-381.

Homans. G. C. (1950). The human group. New York: Harcourt, Brace \& World.

Hubert, L., \& Schultz, J. (1976). Quadratic assignment as a general data analysis strategy. British Journal of Mathematical and Statistical Psychology, 29, 190-241.
Hulin, C. L., \& Roznowski, M. (1985). Organizational technologies: Effects on organizations' characteristics and individuals' responses. In B. M. Staw \& L. L. Cummings (Eds.), Research in Organizational Behavior, 7, 39-85. Greenwich, CT: JAI Press.

Katz, D., \& Kahn, R. L. (1978). The social psychology of organizations (2nd ed.). New York: Wiley.

Kelso, J. A. S. (1995). Dynamic patterns: The self-organization of brain and behavior. Cambridge, MA: MIT Press.

Kendall, M. G. (1963). Rank correlation methods (3rd ed.). London: Griffin.

Kiesler, S., \& Sproull, S. (1992). Group decision making and communication technology. Organizational Behavior and Human Decision Processes, 52, 96-123.

LaCoursiere, R. B. (1980). The life cycle of groups: Group developmental stage theory. New York: Human Sciences Press.

Lawrence, P. R., \& Lorsch, J. W. (1967). Organization and environment. Boston: Harvard University Press.

Levine, J. M., \& Moreland, R. L. (1990). Progress in small group research. Annual Review of Psychology, 41, 585-634.

Lewin, K. (1951). Field theory in social science. Westport, CT: Greenwood Press.

Linville, P. W., \& Jones, E. E. (1980). Polarized appraisals of out-group members. Journal of Personality and Social Psychology, 38, 689703.

Mann, R. D., Gibbard, G. S., \& Hartman, J. J. (1967). Interpersonal styles and group development. New York: Wiley.

McCollom, M. (1995). Reevaluating group development: A critique of familiar models. In J. Gillette \& M. McCollom (Eds.), Groups in context: A new perspective on group dynamics (pp. 133-154), Lanham, MD: University Press of America.

McGrath, J. E. (1991). Time, interaction, and performance (TIP): A theory of groups. Small Group Research, 22, 147-174.

McGrath, J. E. (1993). The JEMCO workshop: Description of a langitudinal study. Small Group Research, 24, 285-306.

McGrath, J. E., Berdahl, J. L., \& Arrow, H. (1996). Traits, expectations, culture and clout: The dynamics of diversity in work groups. In S. E. Jackson \& M. N. Ruderman (Eds.), Diversity in work teams: Research paradigms for a changing workplace (pp. 17-45). Washington, DC: American Psychological Association.

McGrath, J. E., \& Hollingshead, A. B. (1994). Groups interacting with technology. Newbury Park, CA: Sage.

McGrath, J. E., \& O'Connor, K. M. (1996). Temporal issues in work groups. In M. West (Ed.), Handbook of work group psychology (pp. 25-52), London: Wiley.

Mennecke, B. E., Hoffer, J. A., \& Wynne, B. E. (1992). The implications of group development and history for group support system theory and practice. Small Group Research, 23, 524-572.

Miller, D., \& Friesen, P. H. (1980). Momentum and revolution in organizational adaptation. Academy of Management Journal, 23, 591-614.

O'Connor, K. M., Gruenfeld, D. H, \& McGrath, J. E. (1993). The experience and effects of conflict in continuing work groups. Small Group Research, 24, 362-382.

Pfeffer, J., \& Salancik, G. R. (1978). The external control of organizations: A resource dependence perspective. New York: Harper \& Row.

Poole, M. S., \& Roth, J. (1989a). Decision development in small groups: IV. A typology of decision paths. Human Communication Research, $15,323-356$.

Poole, M. S., \& Roth, J. (1989b). Decision development in small groups: V. Test of a contingency model. Human Communication Research. $15,549-589$.

Ridgeway, C. (1991). The social construction of status value: Gender and other nominal characteristics. Sncial Forces, 70, 367-386.

SAS Institute, Inc. (1989). SAS/STAT User's Guide (Version 6, 4th ed., Vol. 2). Cary, NC: Author. 
Shiffrin, R. M., \& Schneider, W. (1977). Controlled and automatic human information processing: II. Perceptual learning, automatic attending, and a general theory. Psychological Review, 84, 127-190.

Smith, C., \& Gemmill, G. (1991). Change in the small group: A dissipative structure perspective. Human Relations, 44, 697-716.

Steiner, I. D. (1972). Group process and productivity. New York: Academic Press.

Tajfel, H., \& Turner, J. C. (1986). The social identity theory of intergroup behavior. In S. Worchel \& W. G. Austin (Eds.), Psychology of intergroup relations (2nd ed.; pp. 7-24). Chicago: Nelson-Hall.

Trist, E. L., \& Bamforth, K. W. (1951). Some social and psychological consequences of the longwall methods of coal-getting. Human Relations, 4, 3-38.

Tuckman, B. W. (1965). Developmental sequence in small groups. Psychological Bulletin, 63, 384-399.

Tuckman, B. W., \& Jensen, M. A. C. (1977). Stages of small-group development revisited. Group \& Organization Studies, 2, 419-427.

Tushman, M. L., \& Romanelli, E. (1985). Organizational evolution: A metamorphosis model of convergence and reorientation. In B. M. Staw \& L. L. Cummings (Eds.), Research in Organizational Behavior, 7, 171-222. Greenwich, CT. JAI Press. von Bertalanffy, L. (1968). General systems theory (Rev. ed.). New York: George Braziller.

Vroom, V. H., \& Yetton, P. W. (1973). Leadership and decision making. Pittsburgh, PA: University of Pittsburgh Press.

Wanous, J. P., Reichers, A. E., \& Malik, S. D. (1984). Organizational socialization and group development: Toward an integrative perspective. Academy of Management Review, 9, 670-683.

Whetten, D. A. (1987). Organizational growth and decline processes. Annual Review of Sociology, 13, 335-358.

Worchel, S. (1994). You can go home again: Retuming group research to the group context with an eye on developmental issues. Small Group Research, 25, 205-223.

Zucker, L. G. (1977). The role of institutionalization in cultural persistence. American Saciological Review, 42, 726-743.

Zucker, L. G. (1987). Institutional theories of organization. Annual Review of Sociology, 13, 443-464.

Received January 30, 1996

Revision received July 26, 1996

Accepted July 26, 1996

\section{Low Publication Prices for APA Members and Affiliates}

Keeping you up-to-date. All APA Fellows, Members, Associates, and Student Affiliates receive-as part of their annual dues-subscriptions to the American Psychologist and $A P A$ Monitor. High School Teacher and International Affiliates receive subscriptions to the $A P A$ Monitor, and they may subscribe to the American Psychologist at a significantly reduced rate. In addition, all Members and Student Affiliates are eligible for savings of up to $60 \%$ (plus a journal credit) on all other APA journals, as well as significant discounts on subscriptions from cooperating societies and publishers (e.g., the American Association for Counseling and Development, Academic Press, and Human Sciences Press).

Essential resources. APA members and affiliates receive special rates for purchases of APA books, including the Publication Manual of the American Psychological Association, and on dozens of new topical books each year.

Other benefits of membership. Membership in APA also provides eligibility for competitive insurance plans, continuing education programs, reduced APA convention fees, and specialty divisions.

More information. Write to American Psychological Association, Membership Services, 750 First Street, NE, Washington, DC 20002-4242. 